ORIGINAL ARTICLE

\title{
Evaluation of an evidence based patient educational booklet for management of whiplash associated disorders
}

\author{
T McClune, A K Burton, G Waddell
}

See end of article for authors' affiliations (n)

Correspondence to: MrT McClune, 30 Queen Street, University of Huddersfield, Huddersfield HDl 2SP, UK; tim@ spineresearch.org.uk

Accepted for publication 2 October 2002
Objectives: This study aimed to develop and evaluate an evidence based educational booklet on whiplash associated disorders.

Methods: A comprehensive review of the available scientific evidence produced a set of unambiguous patient centred messages that challenge unhelpful beliefs about whiplash and promote an active approach to recovery. These messages were incorporated into a novel booklet, which was then evaluated qualitatively for end user acceptability and its ability to impart the intended messages, and quantitatively for its ability to improve beliefs about whiplash and what to do about it. The subjects comprised people attending accident and emergency or manipulative practice with a whiplash associated disorder, along with a sample of workers without a whiplash associated disorder $(n=142)$.

Results: The qualitative results showed that the booklet was considered easy to read, understandable, believable, and conveyed its key messages. Quantitatively, it produced a substantial statistically significant improvement in beliefs about whiplash among accident and emergency patients (mean 6.5, 95\% $\mathrm{Cl} 3.9$ to 9.1, $\mathrm{p}<0.001$ ), and among workers (mean 9.4, 95\% Cl 7.9 to 10.9, $\mathrm{p}<0.001$ ), but the shift in the more chronic manipulation patients was substantially smaller (mean 3.3, 95\% Cl 0.5 to $6.1, \mathrm{p}<0.05$ ).

Conclusions: A rigorously developed educational booklet on whiplash (The Whiplash Book) was found acceptable to patients, and capable of improving beliefs about whiplash and its management; it seems suitable for use in the accident and emergency environment, and for wider distribution at the population level. A randomised controlled trial would be required to determine whether it exerts an effect on behaviour and clinical outcomes.
W hiplash associated disorders (WAD) after road traffic accidents remain a substantial clinical and social problem. Although many cases of WAD seem to recover within days or weeks with no lasting effects, ${ }^{1}$ UK figures indicate that around $50 \%$ of patients do not recover by three months, ${ }^{2}$ and $25 \%$ have residual disability at six months; ${ }^{3}$ many of these patients remain symptomatic for two years or more. ${ }^{24}$ There is considerable individual variation in recovery rates, ${ }^{5}$ as well as differences across countries, $^{6}$ social groups, ${ }^{7}$ and compensation systems, ${ }^{8}$ suggesting that the progression to chronicity is not primarily driven by physical injury characteristics. A substantial body of evidence points to psychological and social factors as determinants of persisting pain and disability in WAD. ${ }^{5} 910$

The Quebec Task Force on whiplash associated disorders ${ }^{11}$ recommended that the most helpful management approach is likely to include positive advice on a number of parameters including prognosis, fear avoidance beliefs, exercise and sport, and return to work. It is convenient and appropriate to present such information in written form, but that material varies considerably in form and content. In an unpublished survey of 110 National Health Service A\&E departments in UK (A Auty 2001, personal communication), 29 provided examples of advice sheets, leaflets, and booklets that they offered to patients with WAD while 12 specifically indicated they did not use any. Eighteen of the 29 were commercially produced advice cards bearing the name and contact number of a local solicitor. It was found that the advice was generally not evidence based and did not target the fundamental issues identified by the Quebec Task Force.

The Patient's Charter ${ }^{12}$ recognises that patients want and seek information and advice on health complaints, and promises patients the right to that information. A detailed investigation of patient information for a variety of health complaints, $^{13}$ has suggested that good quality information can help promote self care, support treatment choices, and improve effectiveness of clinical care. However, the process for producing accurate, acceptable, and effective patient educational material is far from simple, ${ }^{14}$ and much patient information material exhibits significant flaws (for example, poor general quality, inaccurate, and out of date content, uncertainties ignored, and unreliable information on treatment effectiveness)..$^{13}$

The aim of this study was to rigorously develop an evidence based educational booklet on WAD, and to evaluate its suitability for a range of potential end users. It was hypothesised that the booklet would be acceptable to readers, and that the key messages would produce a positive shift in beliefs about the nature of the injury and what to do about it.

\section{METHODS}

Following recommendations for developing patient information, ${ }^{13}{ }^{14}$ and the development for a similar publication for back pain patients, ${ }^{15}$ the structured development and evaluation process for the new booklet comprised eight essential phases.

\section{Literature review}

A comprehensive review of the scientific literature on WAD was conducted to formulate an evidence based set of patient centred messages for WAD patients, and has been published separately. ${ }^{16}$ Briefly, the review involved a systematic search for papers on whiplash published between 1994 and 2001, from which evidence statements were derived, linked to the literature, and graded for their consistency in order to prioritise the booklets' messages. 


\section{Authoring the text}

With the evidence statements confirmed, a multidisciplinary team of three authors (TM, AKB, GW) compiled the narrative of the booklet. This was written in the simple unambiguous language used successfully for The Back Book, ${ }^{17}$ which deliberately demedicalised the condition and promoted a positive approach with a focus on self help. The key messages can be summarised as: there has been no serious damage; the acute pain will improve relatively quickly; use analgesics and do simple exercises; avoiding activity slows recovery; daily activities and early return to work are helpful; a positive active approach is important to avoid long term problems. (Further details on the evidence statements and derived messages can be found in the previous publication ${ }^{16}$ ).

\section{Peer review}

The draft text was sent to 10 reviewers with a special interest in WAD: orthopaedic surgeon, A\&E consultant, pain consultant, clinical psychologist, research physiotherapist, research osteopath, NHS clinical manager, medical educationalist, scientific editor, and senior solicitor.

\section{Refining of text}

The reviewers made a variety of comments with regard to inclusion/exclusion of material and justification of messages. Their suggestions were fully discussed between by the authors; most were accepted and the text was revised accordingly.

\section{Format and graphics}

The format of the text and layout of the booklet were decided in conjunction with professional design experts from the proposed publisher (The Stationery Office), and a graphic artist provided contemporary illustrations. A mock up version of the booklet with full artwork and revised text was printed for the end user evaluations.

\section{End user evaluation}

The evaluation process was both qualitative and quantitative, involving evaluation of the overall acceptability, and comprehension of the messages, together with measurement of the effect on beliefs about WAD. Samples of convenience were drawn from three population groups: workers without current WAD $(\mathrm{n}=79)$; WAD patients attending A\&E $(\mathrm{n}=50)$; WAD patients attending private manipulative (osteopathic) practice $(n=13)$. Steps were taken to encourage response to the questionnaires; the workers were told that their response would generate a donation to charity, while the patients were offered a book token.

The "acceptability" and "comprehension" questionnaires have been described previously for a similar purpose, ${ }^{15}$ while beliefs were assessed using the Whiplash Beliefs Questionnaire (WBQ) which was based closely on the Back beliefs Questionnaire (BBQ) previously validated for low back pain. ${ }^{18}$

The acceptability questionnaire was a tick box instrument inquiring on issues such as ease of reading, length, clarity, informative content, and believability. The comprehension questionnaire comprised open-ended questions inquiring on the messages and their perceived effect; subjects were asked to state the most important perceived messages, and also how the booklet might change what they would do about a whiplash injury. The WBQ explores beliefs and attitudes about the inevitable consequences of WAD, which are scored on a five point Likert scale ranging from "completely agree" to "completely disagree". There are nine questions, so possible scores range from 9 (representing complete agreement with all statements) to 45 (representing complete disagreement); lower scores indicate more positive beliefs.
Principal components analysis confirmed that this new instrument comprised the single psychometric dimension found for the BBQ.

Participants were given an information sheet describing the evaluation process and their part in it. To assess baseline beliefs about WAD, each participant was given the WBQ to complete. They were then given the booklet and asked to read it carefully; after a few days they were asked to fill out the qualitative questionnaires and a second WBQ.

\section{Final refinement of booklet}

The qualitative evaluation raised slight concerns in respect of readability, length, and believability (see results). A number of revisions were made to address those matters.

\section{Publication}

Agreement was reached with The Stationery Office to obtain an international standard book number, secure appropriate cataloguing, and facilitate distribution. The final draft of the text and graphics was printed and published as a 28 page booklet entitled The Whiplash Book. ${ }^{19}$

\section{RESULTS}

One hundred and forty two subjects (aged 16 to 64 years) returned evaluation questionnaires. The responses to the acceptability questionnaire are given in table 1. Complete responses were available from 110 subjects. For all sections the vast majority gave positive responses, indicating a high level of acceptability. Two sections gave useful feedback on the presentation: although none of the respondents found the draft booklet difficult to read, 76\% considered it "quite" easy as compared with "very" easy to read, and 15\% considered it too long. Two sections were helpful regarding the content: most respondents $(86 \%)$ said they gained new information, but $14 \%$ either felt they knew the information already or did not find it helpful; the messages were said to be believable by $86 \%$, but $14 \%$ believed only some or none of the messages.

The results from the comprehension questionnaire indicated that respondents generally understood the key messages in the booklet. Of the 110 respondents, $85 \%$ recalled at least one of the primary messages (some respondents reported more than one message). The predominant messages recalled were: "keep active/do exercises" - 60\%; "permanent damage is rare/expect a good prognosis" $-24 \%$; "take control yourself"- $22 \%$. Two people (1.8\%) did not recall any message. In terms of behavioural influence, $77 \%$ of

Table 1 Subjects' responses to the acceptability questionnaire $(n=110)$

\begin{tabular}{ll}
\hline Responses & $\%$ \\
\hline Very easy to read & 24 \\
Quite easy to read & 76 \\
I found it interesting & 99 \\
I thought the information was clear & 98 \\
I learned some new, helpful things & 86 \\
I knew most of it anyway & 12 \\
Length is about right & 81 \\
It is too long & 15 \\
I believed most of what it said & 86 \\
I believed some of what it said & 13 \\
The pictures helped explain things better & 96 \\
The exercises were clearly explained and easy & 99 \\
to follow & 98 \\
I think it will help people & 98 \\
I would recommend it to someone if they had & \\
a car accident & 96 \\
I liked the overall presentation & \\
\hline
\end{tabular}


Table 2 Mean values (SD) for Whiplash Beliefs Questionnaire scores before and after reading the draft booklet, for the three groups of subjects, together with $95 \%$ confidence intervals for the shifts in score (lower scores represent more positive beliefs: a score of 9 represents complete belief in statements, while 45 represents complete disbelief)

\begin{tabular}{lllll}
\hline & Before & After & Shift & $95 \% \mathrm{Cl}$ \\
\hline Workers $(n=75)$ & $24.2(6.4)$ & $14.9(5.6)$ & $9.4(6.6)$ & 7.9 to 10.9 \\
A\&E patients $(n=24)$ & $21.1(5.8)$ & $14.7(4.4)$ & $6.5(6.1)$ & 3.9 to 9.1 \\
Manipulation patients $(n=12)$ & $24.8(6.0)$ & $21.5(7.8)$ & $3.3(4.4)$ & 0.5 to 6.1 \\
Overall $(n=111)$ & $23.6(6.3)$ & $15.5(6.0)$ & $8.1(6.6)$ & 6.9 to 9.3 \\
\hline
\end{tabular}

Statistical significance of differences between mean scores tested by two sided paired $t$ test: $p<0.001$, except for the shift experienced by the manipulation patients where $\mathrm{p}<0.05$.

subjects reported that the booklet would change what they would do if they experienced a WAD (some respondents reported more than one influence). The predominant reported behaviours were: "avoid inactivity/do exercises"$67 \%$; "be positive about speed of recovery"-20\%. Only $2 \%$ said they would go to GP and 6\% reported the booklet would not effect what they did. Overall, two people $(1.8 \%)$ expressed a hostile response to the messages, considering them dangerous or useless.

One hundred and eleven subjects (78\%) completed WBQ scores both before and after reading the draft booklet. The results, tabulated by study group, are given as means and $95 \%$ confidence intervals (95\% CI) in table 2 . There was a statistically significant improvement in belief scores for all three groups, although the magnitude differed between groups. The greatest mean shift occurred in the workers followed by the A\&E patients, while the osteopathic patients showed the smallest shift. A one way analysis of variance revealed there was a statistically significant difference in mean shift between the workers and the manipulation patients $(p=0.007,95 \%$ CI 1.4 to 10.7 ), but no significant difference between the shifts for workers and A\&E patients ( $p>0.1,95 \%$ CI 0.6 to 6.4 ). Analysis of variance showed that age and sex had no statistically significant influence either on the baseline WBQ scores or the shift in scores.

\section{DISCUSSION}

So far as we are aware, The Whiplash Book is the first evidence based patient educational booklet for WAD that has been developed and evaluated in a structured fashion. To ensure accuracy and currency, patient centred messages were derived from a comprehensive review of the scientific literature. ${ }^{16}$ The resultant booklet, having been rigorously developed, peer reviewed, and revised, offers a very different type of patient information for WAD, which challenges the traditional advice based on a biomedical model. Rather, the thrust follows a biopsychosocial model, demedicalises the problem, and promotes an active self management approach, in which the messages are delivered in simple unambiguous language.

Positive end user perceptions of style, presentation, and content are seen as a necessary feature of effective patient educational material. ${ }^{14}$ The evaluation showed that the novel approach adopted for this booklet is well accepted by patients, that the intended messages are assimilated, and that that is associated with the hypothesised improvement in beliefs about the consequences of whiplash.

It is of some interest that the three subject groups differed in their belief shift after reading the booklet. The largest change occurring in the non-injured workers may indicate that an absence of injury increases the believability of the messages. Conversely, the small change in the manipulation patients may be the result of the relative chronicity of their symptoms; it is reasonable to suppose they had more entrenched negative beliefs that were more difficult to overcome. Despite their acute symptoms the A\&E patients showed a substantial improvement in beliefs. Arguably, the earlier a patient receives the information, the greater the chance of improving beliefs, while broadcasting the information to non-patients may be helpful in changing general (cultural) beliefs about whiplash.

Although encouraging, these results should be viewed tentatively. The subjects were not randomly selected, not all those approached completed the evaluation forms, and there was no control group. Thus, there is the possibility of bias, and generalisability of the results could be questioned. While it is not possible to compare the belief shifts with previous data from WAD patients, the shifts found here correspond with those found for a similar booklet on back pain. ${ }^{15} 20$

In summary, The Whiplash Book represents a useful adjunct to the set of evidence based clinical messages described in a previous paper. ${ }^{16}$ Indeed, educational experts advise that a coordinated approach, in which physicians and therapists all give the same information and advice, and use consistent educational material to reinforce that message, is likely to have a more powerful effect than either in isolation. ${ }^{21}$ While it is not unreasonable to expect an improvement in beliefs to be mirrored in behavioural change and clinical outcomes, the answer to that question rightly will require a randomised controlled trial.

\section{ACKNOWLEDGEMENTS}

We thank the Occupational Health Department at British Petroleum in Aberdeen, the A\&E Department at Huddersfield Royal Infirmary, and Burton Sykes osteopathic practice in Huddersfield for their help in accessing the subjects. We are grateful to Debbie McStrafick for administration of the evaluation study.

\section{Authors' affiliations}

T McClune, A K Burton, G Waddell, Spinal Research Unit, University of Huddersfield, Huddersfield, UK

Funding: The Association of British Insurers gave financial support for the literature review and development of the booklet, while The Stationery Office bore the publishing costs

Conflicts of interest: none declared

\section{REFERENCES}

1 Suissa S, Harder S, Veilleux M. The relation between initial symptoms and signs and the prognosis of whiplash. Eur Spine J 2001;10:44-9.

2 Gargan MF, Bannister GC. The rate of recovery following whiplash injury. Eur Spine J 1994;3:162-4.

3 Galasko CS. The cost of whiplash associated disorders. In: Gunzburg R, Szpalski M, eds. Whiplash injuries: current concepts in prevention, diagnosis and treatment of the cervical whiplash syndrome. Philadelphia: LippincottRaven, 1998:283-90.

4 Maimaris C, Barnes MR, Allen MJ. Whiplash injuries of the neck: a retrospective study. Injury 1998;19:393-6.

5 Mayou R, Bryant B. Outcome of whiplash neck injury. Injury 1996;27:617-23.

6 Obelieniene D, Schrader H, Bovim G, et al. Pain after whiplash: a prospective controlled inception cohort study. J Neurol Neurosurg Psychiatry 1999;66:279-83. 
7 Virani SN, Ferrari R, Russell AS. Physician resistance to the late whiplash syndrome. J Rheumatol 2001;28:2096-9.

8 Cote P, Cassidy JD, Carroll L, et al. A systematic review of the prognosis of acute whiplash and a new conceptual framework to synthesize the literature. Spine 2001:26:E445-58.

9 Gargan M, Bannister G, Main C, et al. The behavioural response to whiplash injury. J Bone Joint Surg 1997;79-B:523-6.

10 Cote $\mathbf{P}$, Hogg-Johnson S, Cassidy JD, et al. The association between neck pain intensity, physical functioning, depressive symptomatology and time-to-claimclosure after whiplash. J Clin Epidemiol 2001;54:275-86.

11 Spitzer WO, Skovron ML, Salmi LR, et al. Scientific monograph of the Quebec Task Force on whiplash-associated disorders: redefining "whiplash" and its management. Spine 1995;20(suppl):8-73S

12 Department of Health. The patient's charter London: HMSO 1992

13 Coulter A, Entwistle V, Gilbert D. Informing patients. An assessment of the quality of patient information materials. London: Kings Fund, 1998.

14 Coulter A. Evidence based patient information. BMJ 1998;317:225-6.
15 Burton AK, Waddell G, Burtt $R$, et al. Patient educational material in the management of low back pain in primary care. Bull Hosp Jt Dis 1996;55:138-41.

16 McClune T, Burton AK, Waddell G. Whiplash associated disorders: a review of the literature to guide patient information and advice. Emerg Med J 2002; 19:499-506.

17 Roland M, Waddell G, Klaber-Moffett J, et al. The back book. Norwich: The Stationery Office, 1996 (http://www.clicktso.com).

18 Symonds TL, Burton AK, Tillotson KM, et al. Do attitudes and beliefs influence work loss due to low back trouble? Occup Med 1996:46:25-32.

19 Waddell G, Burton AK, McClune T. The whiplash book. Norwich: The Stationery Office, 2001 (http://www.clicktso.com).

20 Burton AK, Waddell G, Tillotson KM, et al. Information and advice to patients with back pain can have a positive effect: a randomized controlled trial of a novel educational booklet in primary care. Spine 1999;24:2484-91.

21 Grimshaw JM, Russell IT. Effect of clinical guidelines on medical practice: a systematic review of rigorous evaluations. Lancet 1993;342:1317-22. 